\title{
DESENVOLVIMENTO DE UMA UNIDADE CONTROLADORA DE PROCESSOS DE SECAGEM SOLAR DE BIOMASSA
}

Flávia de Carvalho Oliveia ${ }^{(1)}$ (flaviacarvalhooliveira@ hotmail.com)

Andrea L. T. Charbel ${ }^{(2)}$ (andreacharbel@ufsj.edu.br)

\footnotetext{
${ }^{(1)}$ UFSJ - Departamento de Engenharia Elétrica - Praça Frei Orlado, 170, Centro, São João del Rei, MG

(2) UFSJ - Departamento de Ciências Térmicas e dos Fluidos - Praça Frei Orlado, 170, Centro, São João del Rei, MG
}

RESUMO: Com a crescente crise energética mundial e as urgentes questões ambientais e climáticas, tem ocorrido a transição da matriz energética em busca por novas fontes de energia limpa, destacando-se, entre estas, a energia solar e a biomassa. Pretende-se aproveitar a biomassa composta por resíduos alimentares orgânicos que devem ser secos a fim de serem utilizados como insumo energético sólido. A secagem é necessária uma vez que o teor de umidade reduz o poder calorífico, interferindo no aproveitamento energético do material. $O$ processo de secagem da biomassa será realizado em um secador solar direto, com e sem a presença do controle de temperatura interna do mesmo. O controle é necessário devido à intermitência da radiação solar e à consequente variação de temperatura do ar de secagem, o que pode comprometer tanto a qualidade do produto como o tempo do processo. O controle foi feito através do uso do microprocessador Arduíno acoplado a sensores de temperatura e de umidade do ar e do produto dispostos no interior do equipamento. Os experimentos foram feitos com o secador vazio e cheio com amostras de biomassa de banana. A comparação das variáveis temperatura e umidade medidas no interior do secador com o controle e sem o controle de temperatura tornaram perceptíveis as contribuições $e$ vantagens de se realizar a secagem com o controle de temperatura.

PALAVRAS-CHAVE: Biomassa, secagem, controle, arduino.

\section{INTRODUÇÃO}

A necessidade energética cresce na mesma proporção da população mundial, acarretando problemas ambientais e climáticos, como o aquecimento global, implicando na necessidade de transição da matriz energética mundial para uma matriz mais limpa, com maior participação de fontes renováveis como a energia solar, eólica, hídrica e de biomassa, entre outras alternativas.

No que se refere às fontes renováveis, o aproveitamento energético como insumo energético sólido do Resíduo Sólido Urbano (RSU) é, de fato, uma alternativa promissora e elemento importante regionalmente ou localmente, não devendo ser desconsiderada (EPE, 2008). Algumas características destes resíduos, como o excesso de umidade, influenciam negativamente o desempenho energético da biomassa o que torna essencial uma etapa de secagem anterior à queima do material FIMACO (2018).

\section{COEN - Congresso de Engenharias da UFSJ Interconexão.}



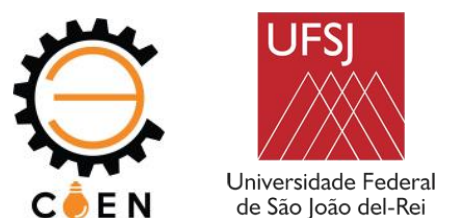

A construção de coletores solares diretos com circulação natural é uma interessante alternativa para o projeto de secadores solares de baixo custo e maior eficiência (Souza, 2012), e essa técnica pode ser estendida à secagem de RSU, proporcionando a melhoria das qualidades energéticas da biomassa combustível resultante.

Segundo Alves (2010) a eficiência térmica dos secadores solares pode ser estudada através do conhecimento de variáveis como temperatura, umidade e radiação solar incidente no plano do coletor. No presente estudo são utilizados micros controladores, como por exemplo, o Arduino, para fazer a medição e controle da temperatura durante todo o processo de secagem da biomassa.

\section{OBJETIVOS}

O objetivo do trabalho foi o desenvolvimento de rotinas na placa Arduino que permitam não só medir como também controlar e manter uma temperatura pré-definida uniforme no interior do secador, fazendo uso de lâmpadas e coolers no caso da necessidade de aquecimento ou resfriamento do ar, respectivamente.

\section{REFERENCIAL TEÓRICO}

O processo de secagem surgiu da necessidade de conservação dos alimentos, sendo posteriormente estendido como etapa de processos em diferentes segmentos, como nas indústrias farmacêuticas, de alimentos, tecidos, tinto, minérios, entre tantas outras. Neste processo a perda de material líquido ocorre através da associação dos fenômenos de transferências de calor e de massa, quando o aumento da temperatura do produto provoca aumento da pressão de vapor interna e consequente aumento da difusividade da água nas formas líquida e vapor (BARBOSA , 2011).

Existem várias formas de secagem, entre elas: a secagem natural, quando o produto é exposto diretamente ao vento e ao sol para a remoção da umidade do produto Maia (1995), e a secagem artificial, na qual é utilizada uma fonte de calor variável e o processo é executado com o auxílio de alternativas mecânicas ou elétricas (secadores), podendo o ar de secagem ser forçado ou não através do produto (CAVARIANI, 1996). Os secadores podem ser de diferentes tipos, dentre eles, do tipo cabine, túnel, esteira, leito fluidizado ou leito de jorro e os do tipo bandeja, que, 
segundo Silva (2005) são caracterizados pela simplicidade de construção, de operação, e também pelo baixo custo de manutenção, além de permitirem a exposição uniforme do material sobre uma bandeja com fundo tipo tela.

Como explica Bezerra (2001), o funcionamento do secador solar se baseia em um fluxo de ar que percorre de forma natural ou forçada o secador e que, durante seu trajeto, é aquecido por exposição à radiação solar, Os produtos perdem umidade ao entrar em contato com o ar assim aquecido.

Os secadores solares podem ser de exposição direta, quando o material é disposto no coletor do secador de forma que receba a radiação solar diretamente, de exposição indireta, quando o material é acondicionado em uma câmara por onde circula o ar aquecido no coletor, ou ainda, mistos, quando as duas características são combinadas Silva (2005).

Nos secadores solares, devido à intermitência da radiação solar incidente no plano do secador, as temperaturas tanto do ar de secagem como do produto estão expostas a grandes variações, o que pode comprometer a qualidade do produto seco. Faz-se necessário, então, o monitoramento e controle das condições de operação do processo de acordo com as características do material que se deseja secar. Neste trabalho a medição da temperatura e o seu controle são feitos por meio do Arduino, que é uma plataforma eletrônica open source, ou seja, qualquer pessoa pode modificar e distribuir a programação (Opensource, 2016) e de prototipagem baseada em hardware e software flexíveis e de fácil utilização (ARDUINO, 2016).

O Arduino é composto por um micro controlador Atmel, circuitos de entrada/saída de fácil conexão a um computador e programado via IDE (Integrated Development Environment, ou, Ambiente de Desenvolvimento Integrado) utilizando uma linguagem baseada em $\mathrm{C} / \mathrm{C}++$.

Utilizando o ambiente de programação IDE é possível construir inúmeras programações, as quais são transferidas ao Arduino por meio de um cabo USB. Entretanto, é importante conhecer as duas partes que compõem a estrutura básica do Arduino, que são o setup() - Onde é feita a configuração das opções iniciais do seu programa e o $\operatorname{loop}()$ - Onde são inseridos os comandos a serem executados.

Existem vários modelos de Arduino entre eles o do tipo Uno, que é um dos mais simples devido à baixa capacidade de armazenamento e processamento $\mathrm{O}$ Arduino Uno possui processador 
ATMEGA328, 14 portas digitais, sendo que 6 delas podem ser usadas como saídas PWM, e 6 portas analógicas (ARDUINO, 2016).

Encontra-se no mercado uma vasta variedade de sensores que podem ser acoplados ao Arduíno. Sensores, conforme definido por Steffen (2016), são dispositivos eletroeletrônicos que tem a propriedade de transformar em sinal elétrico a variação de uma grandeza física que está relacionada a uma ou mais propriedades do material de que é feito o sensor.

No processo de secagem é importante o controle da temperatura e da umidade, tanto do ar como do produto. Desta forma, foram utilizados três tipos de sensores, como se segue:

O sensor DHT22, também chamado de AM2302. É um sensor de temperatura e umidade do ar que utiliza um termistor e um sensor capacitivo, conectados a um controlador de oito bits que produz um sinal digital serial no pino de dados. Na Figura 1 é possível ver a parte interna do DHT22 e a pinagem do mesmo.

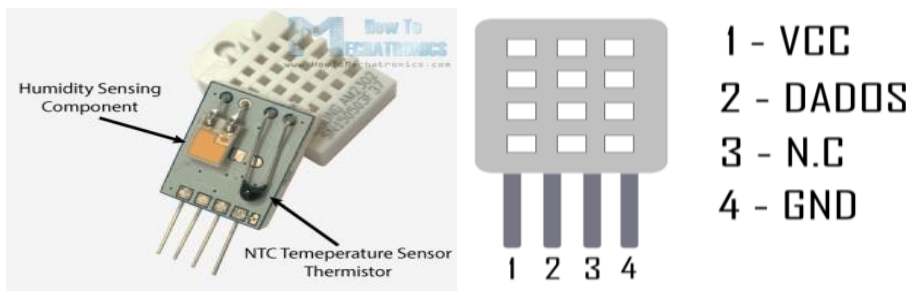

Figura 1. À esquerda, os componentes internos do DHT22 e, à direita, a pinagem do DHT22.

A alimentação recomendada é de $5 \mathrm{~V}$, mas pode ocorrer em 3,3 V. Possui $2.5 \mathrm{~mA}$ de corrente máxima durante a conversão e $100-150 \mu \mathrm{A}$ em standby e quatro pinos com 0.1 " de espaçamento entre eles. Apresenta faixa de medição de temperatura entre -40 a $+80{ }^{\circ} \mathrm{C}$ com $\pm 0,5^{\circ} \mathrm{C}$ de precisão e a faixa de medição de umidade varia entre 0 - $100 \%$, com 2 - 5\% de precisão e resolução de $0,1 \%$ para ambos os casos. O intervalo mínimo entre duas medições consecutivas deve ser de dois segundos.

Outro sensor utilizado é o de temperatura infravermelho IR MLX90614 visto na Figura 2 a seguir. A faixa de medição para temperatura de objetos varia entre $-7{ }^{\circ} \mathrm{C}$ e $380{ }^{\circ} \mathrm{C}$ com precisão de $0,5^{\circ} \mathrm{C}$. É recomendada a alimentação em $5 \mathrm{~V}$. A comunicação com o microcontrolador é feita via interface I2C ocupando apenas 2 pinos do microcontrolador (pinos SCL e SDA), apresenta uma 
saída com resolução de 10bit PWM (Sparkfun) e já é calibrado durante a fabricação, devendo ser instalado entre 3 - $4 \mathrm{~cm}$ de distância do objeto.

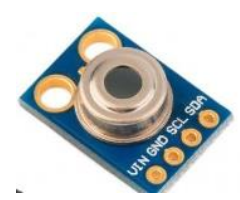

Figura 2. Sensor de temperatura infravermelho MLX90614.

O terceiro sensor utilizado é o sensor de umidade do solo - Higrômetro. Este é composto por uma haste (sonda ou eletrodo) por onde passa uma corrente e que em contato com o material permite estimar a umidade do mesmo, e um pequeno módulo contendo um chip comparador LM393 que vai ler os dados que vêm da sonda e enviá-los para o micro controlador Arduino Uno. Para correto funcionamento este sensor deve ser alimentado em $5 \mathrm{~V}$ e ter uma corrente de $100 \mathrm{~mA}$.

Este sensor oferece duas opções de saída: o pino D0 que fica em nível 0 ou 1 e, o pino A0 que tem uma maior precisão no monitoramento. Este sensor é apresentado na Figura 3.

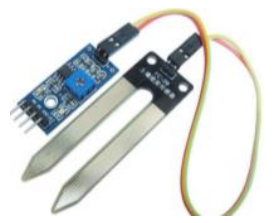

Figura 3. Sensor higrômetro de umidade do solo e módulo comparador.

\section{METODOLOGIA EXPERIMENAL}

De posse de todos os dispositivos e equipamentos foram criados os algoritmos necessários para o funcionamento do protótipo. Em seguida foram confeccionados e alocados os protótipos, permitindo a aquisição de dados para levantamento dos resultados.

O secador utilizado tem dimensões de $100 \mathrm{~cm}$ x $100 \mathrm{~cm}$ x $20 \mathrm{~cm}$ (c x 1 x a) e é construído com placas de material rígido, separadas por isopor (isolante térmico) e todo pintado de preto. No seu interior há uma prateleira de tela metálica, na qual são colocadas as bandejas de amostras e são presos os sensores DHT22. A parte superior é de vidro, conforme visto na Figura 4. 


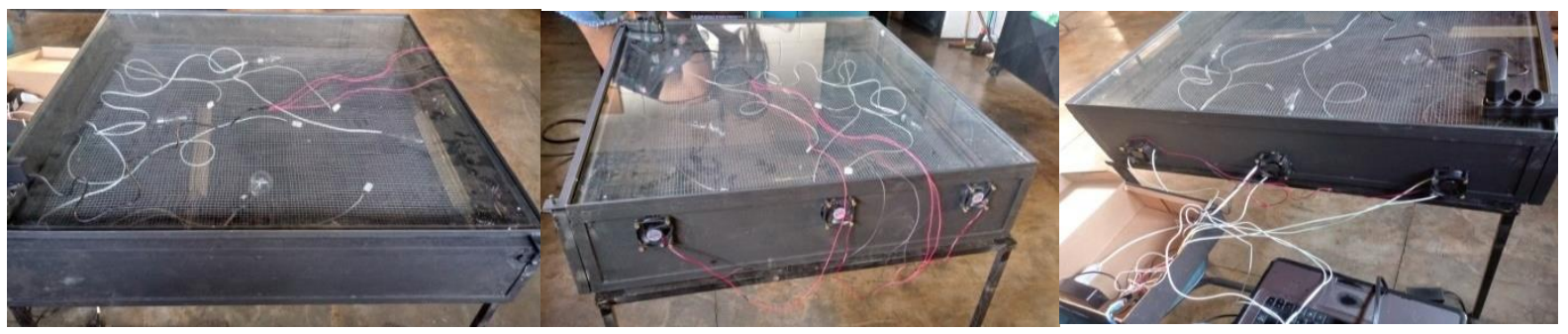

Figura 4. Secador solar utilizado.

Uma das laterais do secador é uma tampa que permite a colocação das amostras e eventuais reparos nos sensores. A lateral paralela à tampa é totalmente fechada. Em cada uma das outras duas laterais há três furos, onde foram alocados três coolers, controlados pelo Arduino, e três exaustores que podem ser utilizados em épocas muito quentes como no verão.

A temperatura interna do secador é uma das mais importantes variáveis no processo de secagem de biomassa e no presente trabalho será monitorada e controlada o tempo todo através do sensor DHT22 e seus valores apresentados em um display LCD.

A temperatura interna medida é usada para controlar o funcionamento de três coolers responsáveis pela redução da temperatura quando esta for superior a $70{ }^{\circ} \mathrm{C}$ e também para ligar quatro lâmpadas fluorescentes, responsáveis por aquecer o ar interno do secador, quando a temperatura interna for inferior a $61^{\circ} \mathrm{C}$. Na Figura 5 abaixo, podem ser vistos parte da programação responsável por controlar as lâmpadas e coolers, o LCD com os valores medidos e as lâmpadas em funcionamento.
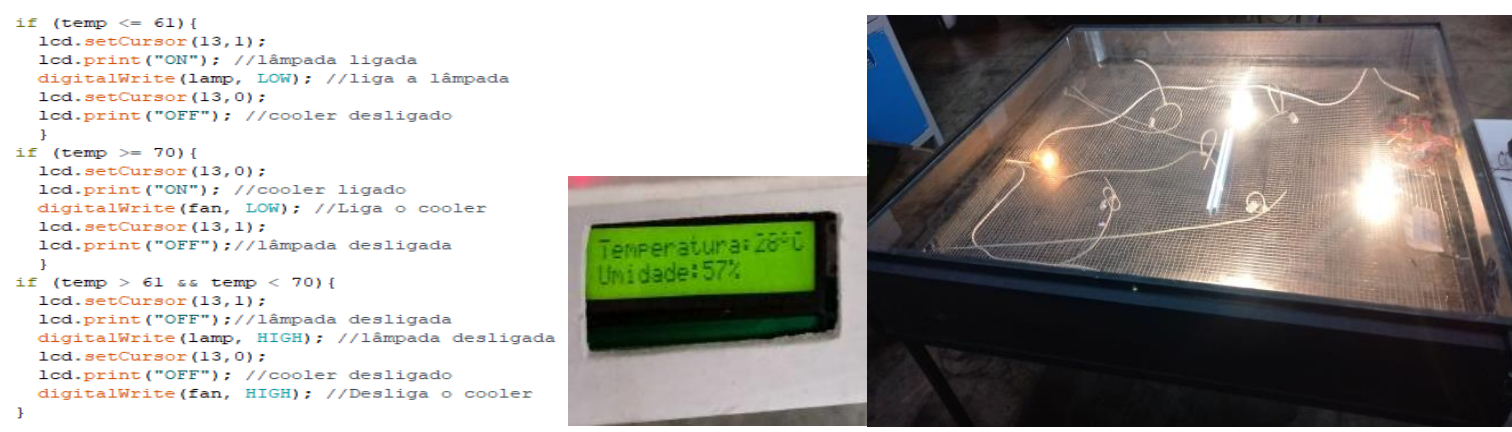

Figura 5. À esquerda, parte da programação utilizada para controle da temperatura, no meio, o LCD com os dados medidos e, à direita, as lâmpadas em funcionamento. 
Para conexão do sensor de temperatura IR MLX90614 na placa Arduino usou-se os pinos analógicos A4 (SDA) e A5 (SCL), que são os pinos de comunicação I2C e para a programação foi utilizada a biblioteca Adafruit MLX90614.

O sensor de umidade do solo foi conectado ao Arduino através do pino A0 do módulo e o pino A0 do Arduino e, para leitura dos dados foi utilizada a função "analogRead". Com o auxílio do comando if obteve-se níveis de umidade, de 0 a 100\%, cada nível de tamanho $1 \%$.

Todas as medições feitas são apresentadas em displays LCD’s 16x2, com backlight verde. Para tanto, é necessário a utilização da biblioteca LiquidCrystal I2C, conforme Figura 8 a seguir.

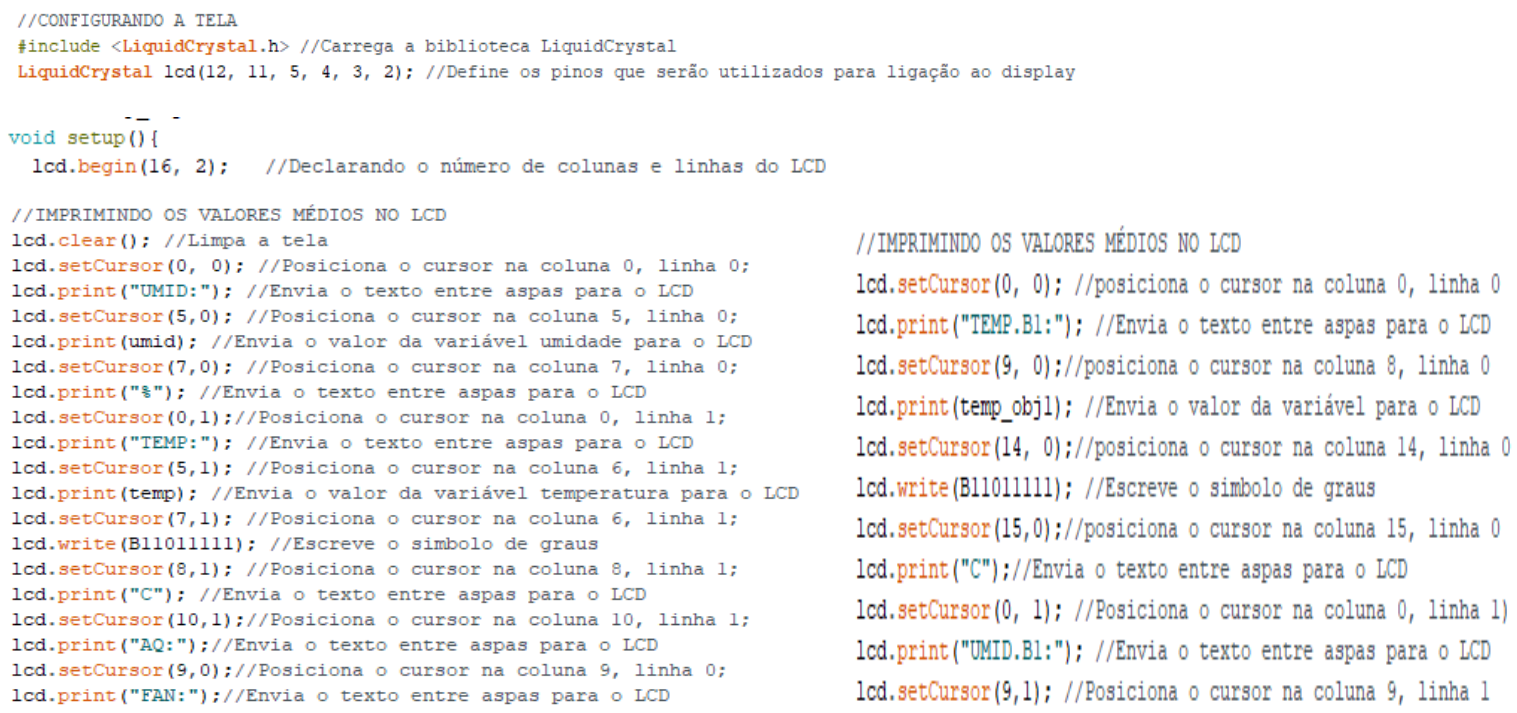

Figura 8. Programação utilizada para configuração e funcionamento do display LCD.

\section{RESULTADOS}

A proposta do projeto é a secagem de biomassa de RSU, mas os testes foram feitos com biomassa de banana, tendo em vista a sua maior uniformidade quando comparada ao RSU. Os testes visaram o estudo do comportamento do secador e do controle via Arduino da variação da temperatura e umidade do ar e do produto, buscando temperaturas mais estáveis do processo de secagem. 
Os dois primeiros dias de testes foram dedicados, respectivamente, ao secador vazio funcionando sem e com o controle de temperatura. Em ambos os dias, foram realizadas as medições de temperatura e umidade do ar durante o período de 08:00h as 17:00h. Os resultados obtidos são apresentados, respectivamente, nas Figuras 9 e 10.

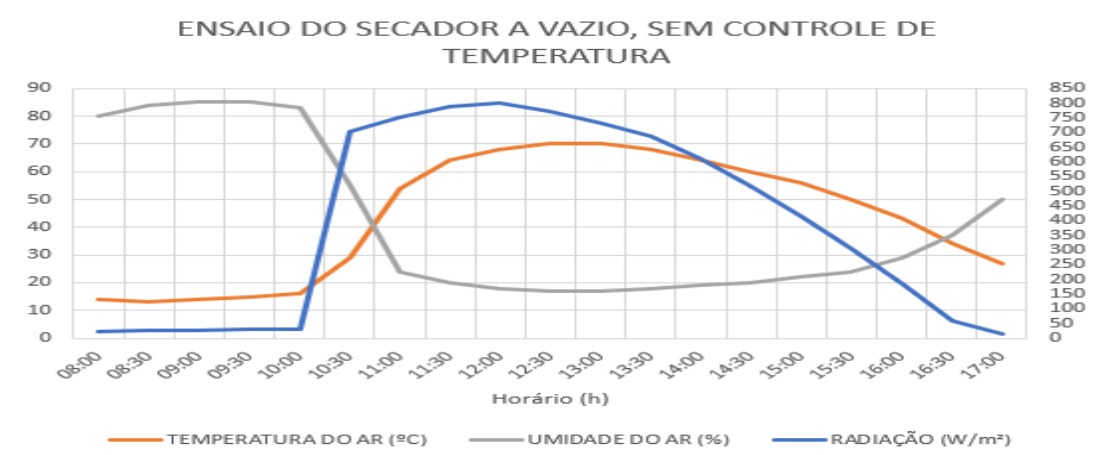

Figura 9. Resultados dos testes do secador a vazio sem controle de temperatura.

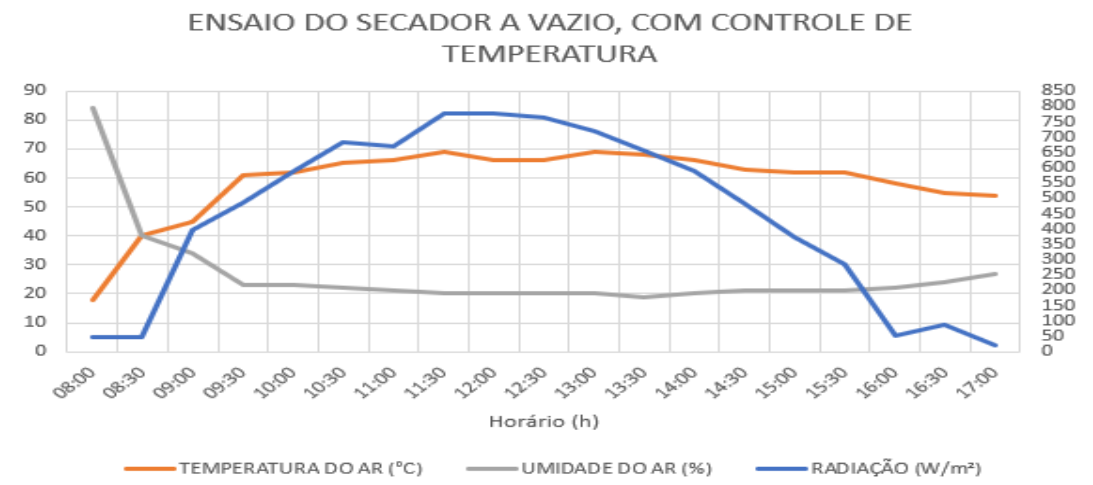

Figura 10. Resultados dos testes do secador a vazio com controle de temperatura.

Comparando-se os dados apresentados nas Figuras 9 e 10, é perceptível a importância do controle para o alcance de um nível de temperatura mais uniforme, na faixa de $60{ }^{\circ} \mathrm{C} \mathrm{a} 70{ }^{\circ} \mathrm{C}$. Podese observar, na Figura 9, que a temperatura se manteve entre $60^{\circ} \mathrm{C}$ e $70^{\circ} \mathrm{C}$ apenas nos horários compreendidos entre 11:30h e 14:30h, decrescendo em seguida devido à queda da radiação solar. Já para o caso do secador a vazio com o controle, a temperatura se manteve entre os limites especificados na programação por um intervalo maior de tempo, entre pouco mais de 9:30h até 16:30h, conforme verificado na Figura 10. 
Foram realizados, também, testes com o secador cheio, onde foram medidas a temperatura e a umidade do ar e a temperatura e a umidade das amostras. No primeiro destes testes, foram utilizadas três bandejas, cada uma contendo $100 \mathrm{~g}$ de banana prata amassada e os resultados são vistos na Figura 11 a seguir. Os testes do secador cheio foram realizados entre 10:00h e 14:00h, ou seja, nos períodos com maior nível de radiação solar.
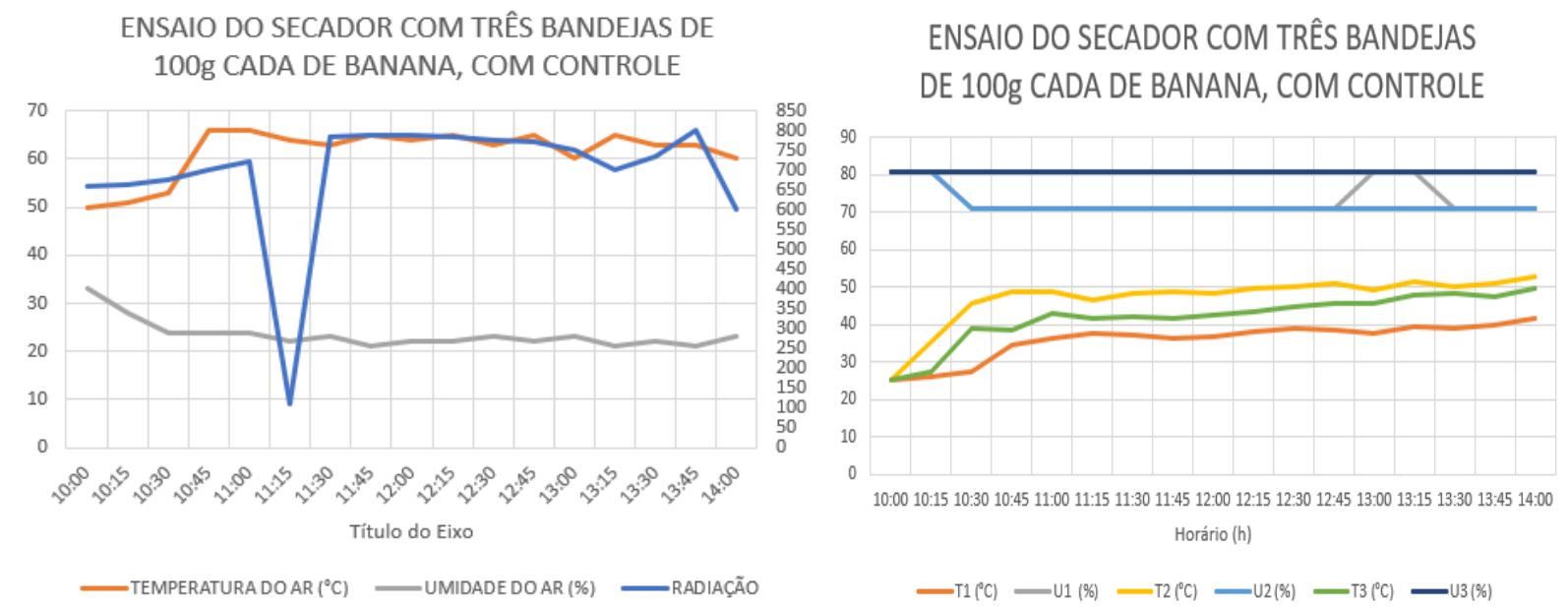

Figura 11. Resultados do secador cheio com amostras de banana amassada: (a) radiação solar, temperatura e umidade do ar; (b) temperaturas e umidades das três amostras

No primeiro teste do secador cheio não foram obtidos resultados satisfatórios, provavelmente devido ao fato de ser utilizada uma massa de $100 \mathrm{~g}$ de banana amassada, quantidade considerada excessiva e que demandaria um tempo de secagem de vários dias uma vez que notou-se a formação de uma crosta externa que dificulta a saída da umidade do produto. Consequentemente, o exterior da amostra estava muito seco e o interior muito úmido. Assim, os dados fornecidos pelo sensor de umidade higrômetro não foram representativos.

Outro motivo de não ter se obtido resultados satisfatórios no primeiro ensaio com o secador cheio, é o fato da programação da medição do sensor higrômetro de umidade do solo ter sido realizada em intervalos de $10 \%$ de umidade. Isto fez com que não fosse possível registrar a variação ponto a ponto da umidade, o que é perceptível pela análise da Figura 11.

No segundo dia de teste com o secador cheio, foram utilizadas três bandejas contendo: Bandeja 1: 14,4 g, Bandeja 2: 12,6g e bandeja 3: 14,43g de bananas em rodelas, permitindo uma 
secagem mais uniforme e o sensor de temperatura MLX90614 foi realocado para que este ficasse mais firme e mais perto da amostra. Os resultados das medições são vistos na Figura 12 a seguir.

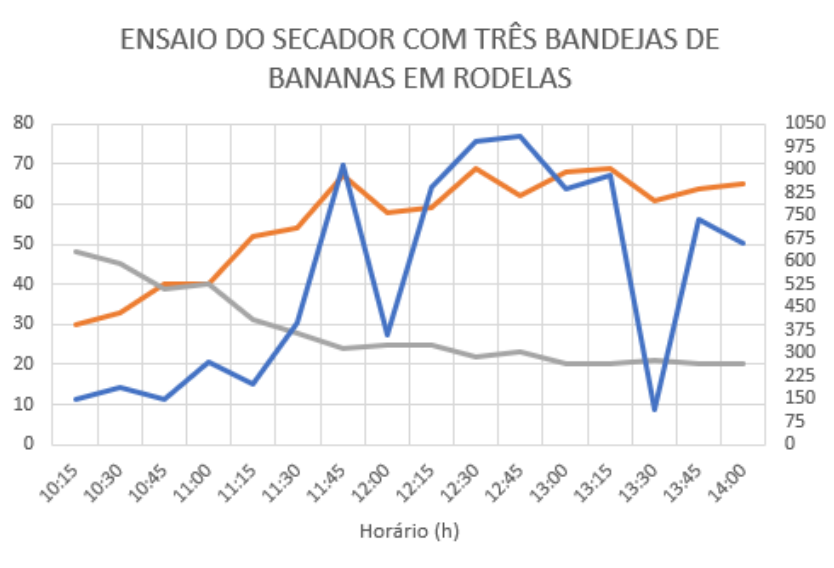

- temperatura interna ( $\left.{ }^{\circ} \mathrm{C}\right)$ —UMidade InTERna (\%) — RADIAÇ̃̃o $\left(\mathrm{W} / \mathrm{m}^{2}\right)$

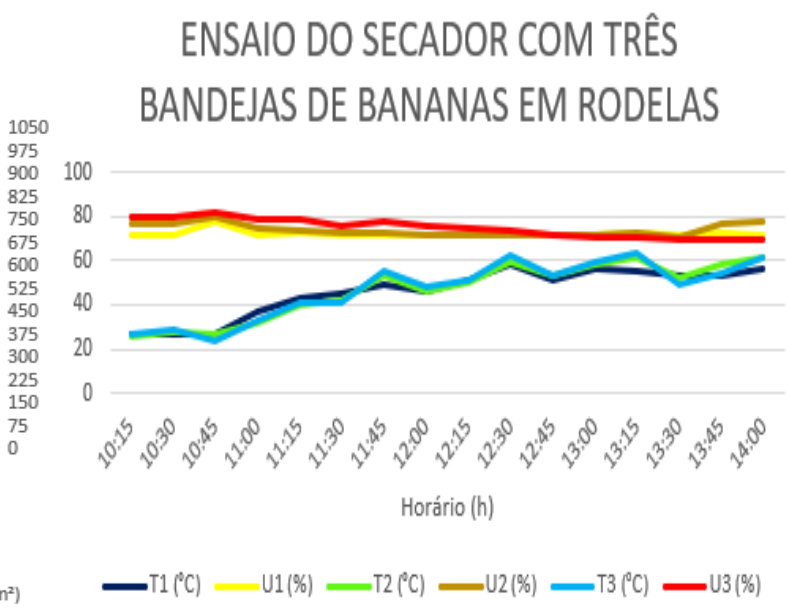

ENSAIO DO SECADOR COM TRÊS BANDEJAS DE BANANAS EM RODELAS

Figura 12. Resultados do teste do secador cheio com três amostras de banana em rodelas.

Na Figura 13 a seguir é possível ver a diferença de secagem entre os dois tipos de amostra utilizada.

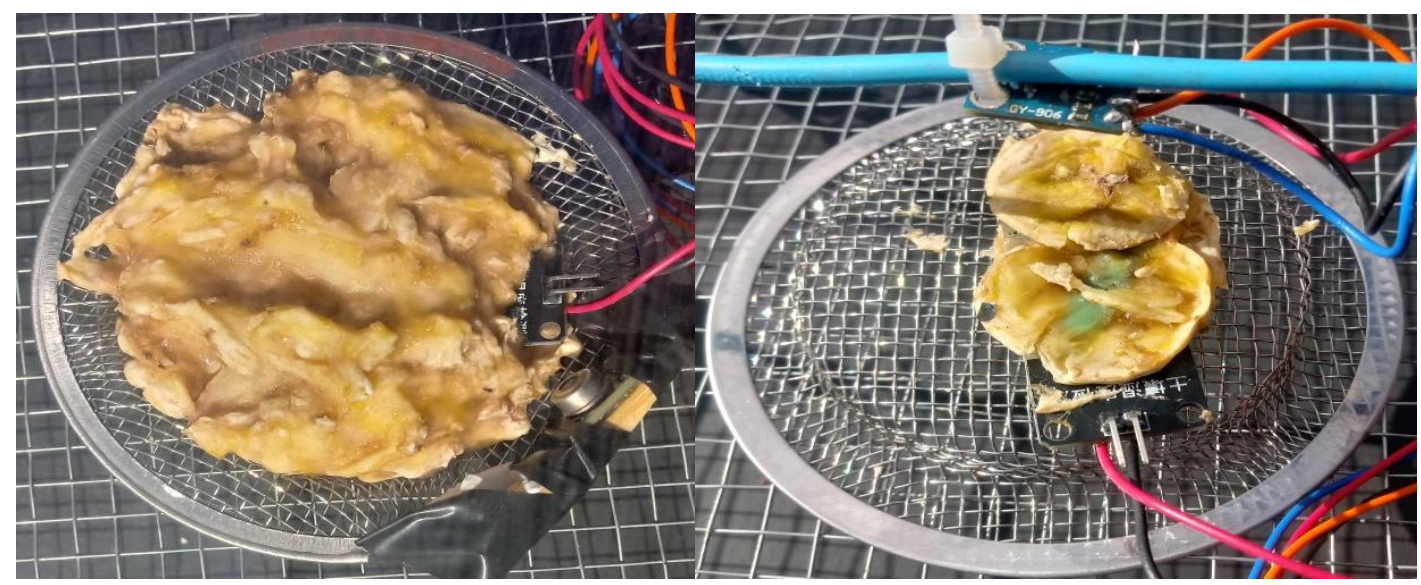

Figura 13. À esquerda, amostra de banana amassada e, à direita, amostra de banana em rodelas.

No segundo teste do secador cheio, a programação do Arduino para aquisição das grandezas do sensor higrômetro de umidade do solo foi modificada para a aquisição da umidade em intervalos 
de $1 \%$, permitindo a visualização da variação de umidade dentro da amostra, conforme Figura 12, corrigindo o problema.

Neste mesmo dia, a fim de confirmar os valores de umidade do produto medidos pelos sensores acoplados ao Arduíno, foram realizadas as pesagens das amostras antes e depois do processo de secagem. Com esses dados foi calculada a umidade final atingida pelas amostras de acordo com as Equações 1, 2, 3 e 4, e os dados medidos e calculados são apresentados na Tabela 1.

$$
\begin{aligned}
& \text { massa }_{\text {agua_inicial }}=\text { massa }_{\text {inicial }} \times \text { umidade }_{\text {inicial }} \\
& m a s s a_{\text {seca }}=\text { massa }_{\text {inicial }}-\text { massa }_{\text {agua_inicial }} \\
& \text { massa }_{\text {agua_final }}=\text { massa }_{\text {final }}-\operatorname{massa}_{\text {seca }} \\
& \text { umidade }_{\text {final }}=\frac{\text { massa }_{\text {agua_final }}}{\text { massa }_{\text {final }}} \times 100 \%
\end{aligned}
$$

Tabela 1. Dados da pesagem das amostras antes e depois do processo de secagem e resultado dos cálculos da umidade final.

\begin{tabular}{|c|c|c|c|c|c|c|c|}
\hline AMOSTRA & $\begin{array}{c}\text { Peso } \\
\text { inicial } \\
(\mathrm{g})\end{array}$ & $\begin{array}{c}\text { Peso } \\
\text { final } \\
(\mathrm{g})\end{array}$ & $\begin{array}{c}\text { Umidade } \\
\text { inicial } \\
(\%)\end{array}$ & $\begin{array}{c}\text { Massa de } \\
\text { água inicial } \\
(\mathrm{g})\end{array}$ & $\begin{array}{c}\text { Massa } \\
\text { seca } \\
(\mathrm{g})\end{array}$ & $\begin{array}{c}\text { Massa de } \\
\text { água final } \\
(\mathrm{g})\end{array}$ & $\begin{array}{c}\text { Umidade } \\
\text { final } \\
(\%)\end{array}$ \\
\hline 1 & 12,6 & 4,71 & 72 & 9,07 & 3,53 & 1,18 & 21,10 \\
\hline 2 & 10,43 & 3,38 & 77 & 8,03 & 2,40 & 0,98 & 29,03 \\
\hline 3 & 10,2 & 3,95 & 80 & 8,16 & 2,04 & 1,91 & 48,35 \\
\hline
\end{tabular}

Os valores da umidade final medida pelo sensor higrômetro foram comparados com a umidade final calculada conforme Tabela 1. Verificou-se, assim, que as medições apresentadas pelo referido sensor não indicam as variações reais do processo e deve ser feita uma calibração ou ele deve ser substituído por outro sensor. A inconformidade das medições apresentadas pelo sensor pode se dever ao fato do tamanho do sensor ser significativo em relação à amostra, interferindo, assim, no processo de secagem, impedindo a passagem da umidade para o ar. Assim, a umidade final a ser considerada é aquela apresentada na Tabela 1. 


\section{CONCLUSÕES}

Os resultados obtidos permitem concluir que o controle da temperatura pode ser feito com o Arduíno. No entanto, os sensores devem ser cuidadosamente estudados e testados experimentalmente a fim de se obter resultados confiáveis e representativos do processo. Como sugestões de trabalhos futuros cita-se, assim, a realização dos testes com amostras de RSU e a definição de outro tipo de sensor de umidade adequado e que não interfira no processo de secagem solar estudado.

\section{AGRADECIMENTOS}

À PROPE/ UFSJ, pela bolsa concedida e pela oportunidade de realização desta pesquisa.

\section{DIREITOS AUTORAIS.}

O autor é o único responsável pelo conteúdo das informações contidas neste artigo.

\section{REFERÊNCIAS}

\section{- Dissertação ou Teses:}

BARBOSA, J. R. P. Estudo da viabilidade de uso de secadores solares fabricados com sucatas de luminárias. Natal, RN: 2011. 70 f. Dissertação (Mestrado) - Universidade Federal do Rio Grande do Norte. Centro de Tecnologia. Programa de Pós-Graduação em Engenharia mecânica.

CAVARIANI, C. Secagem estacionária de sementes de milho com distribuição radial do fluxo de ar. 1996. 85f. Tese (Doutorado em Produção Vegetal) - Esalq-USP.

MAIA, M. Secagem de sementes de azevém anual (Lolium multiflorum Lam.) com ar ambiente forçado. 1995. 108f. Tese (Doutorado em Ciência e Tecnologia de Sementes) - UFPel.

SILVA.J.M; Secagem de pedaços cúbicos de goiaba em Leito de Jorro. (Tese de Doutorado), Campina Grande-PB: Universidade Federal de Campina Grande, 2010. 110p

SOUZA, I. F.: Análise Teórica -Experimental de Secador Solar para Agricultura Familiar por Termografia de Infravermelho e Transformação Integral. Dissertação (Mestrado - Programa de Pós-Graduação em Engenharia Mecânica, COPPE, UFRJ). Rio de Janeiro, 2012, 94p.

- Trabalhos publicados em anais de evento:

CORNEJO, F.E.P; Nogueira,R.J; Nogueira,R.J; Wilberg,V.C; Secagem como Método de Conservação de Frutas. Rio de Janeiro, RJ. 2003.14p. (Embrapa Agroindústria de Alimentos).

- Livros e outras monografias: 

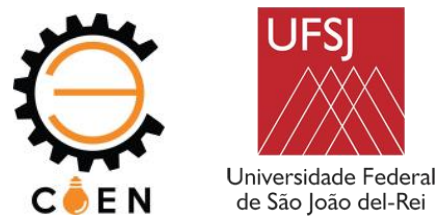

BEZERRA, A. M. Aplicações térmicas da energia solar. João Pessoa: Ed. Universitária UFPB, 2001

DIAS, C. M; MARQUES, W. M; BORGES, S. V; ANCINI, M. C. Efeito da secagem em leito de jorro bidimencional sobre as propriedades físicas e tecnológicas do feijão preto (Phaseolus vulgaris, L.). Ciência e Tecnologia de Alimentos, v. 20, n. 3, p.76-79, 2000.

SILVA, J. S.; BERBERT, P. A. Colheita, secagem e armazenamento. Viçosa: Aprenda Fácil, 1999. 145p. Maio de 2004.

- Páginas de internet:

ARDUINO. Arduino UNO \& Genuino UNO. Disponível em $<$ https://www.arduino.cc/en/Main/ArduinoBoardUno>. Acesso em: 18 fev. 2019.

BLOG ELETROGATE. Disponível em <http://blog.eletrogate.com/wpcontent/uploads/2019/01/Datasheet_DHT22_AM2302.pdf>. Acesso em: 16 maio 2019.

EPE [Empresa de Pesquisa Energética]. NOTA TÉCNICA DEN 06/08. Avaliação Preliminar do Aproveitamento Energético dos Resíduos Sólidos Urbanos de Campo Grande, MS. Rio de Janeiro: EPE, 2008. Disponível em <http://www.epe.gov.br>. Acesso em: 15 fev. 2019.).

FIMACO. Grupo de soluções tecnológicas. Informativo, 27 de julho de 2018 - Entenda porque a secagem da Biomassa é um processo crucial. Disponível em <https://www.fimaco.com.br/blog/category/biomassa-e-secagem/>. Acesso em: 25 jan. 2019.

LIMA, G. F. 'Controle de temperatura de um sistema de baixo custo utilizando a placa Arduino. Disponível em <http://www2.ifrn.edu.br/ocs/index.php/congic/ix/paper/viewFile/765/134>. Acesso em: 18 fev. 2019.

Smart Projects: Disponível em < https://www.smartprojectsbrasil.com.br/sensor-de-temperaturainfravermelho-mlx90614>. Acesso em 16 maio 2019

SPARKFUN. Disponível em <https://www.sparkfun.com/datasheets/Sensors/Temperature/MLX90614_rev001.pdf>. Acesso em 16 maio 2019

\title{
DEVELOPMENT OF A CONTROLLER UNIT OF BIOMASS SOLAR DRYING PROCESSES
}

\author{
Flávia de Carvalho Oliveia ${ }^{(1)}$ (flaviacarvalhooliveira@ hotmail.com) \\ Andrea L. T. Charbel ${ }^{(1)}$ (andreacharbel@ ufsj.edu.br) \\ (1) UFSJ - Departamento de Ciências Térmicas e dos Fluidos - Praça Frei Orlado, 170, Centro, São João del Rei, MG
}

ABSTRACT: With the increasing global energy crisis and the urgent environmental and climatic issues, the transition from the energy matrix to the search for new sources of clean energy has taken place, among them solar energy and biomass. It is intended to take advantage of biomass composed of organic food waste that must be dried in order to be used as a solid energy input. Drying is necessary since the moisture content reduces the calorific value, interfering in the energy utilization of the material. The drying process of the biomass will be carried out in a direct solar dryer, with and without the presence of the internal temperature control of the same one. Control is necessary due to the intermittent solar radiation and consequent temperature variation of the drying air, which can compromise both product quality and 
process time. The control was done through the use of the Arduino microprocessor coupled to temperature and humidity sensors of the air and the product arranged inside the equipment. The experiments were done with the dryer empty and filled with samples of banana biomass. The comparison of the variables temperature and humidity measured inside the dryer with the control and without the temperature control made perceptible the contributions and advantages of drying with the temperature control.

KEYWORDS: Biomass, drying, control, arduíno. 